\title{
Spontaneous Temporal Lobe Encephalocele Within the Sphenoid Sinus
}

\author{
Mohammed Dhaha, ${ }^{1}$ Abdelhafidh Sliman, ${ }^{2}$ Nadhir Karmeni, ${ }^{2}$ Sawsen Dhambri, ${ }^{2}$ Jalel Kallel ${ }^{2}$ \\ ${ }^{1}$ Institut Salah-Azaiz, Tunis, Tunisia \\ ${ }^{2}$ National Institute of Neurology, Tunis, Tunisia
}

Correspondence to: Dr. Mohammed Dhaha; email: dhaha.mohamed87@gmail.com

Received: 18 November 2019; Revised: 22 March 2020; Accepted: 08 May 2020; Available online: 21 June 2020

\begin{abstract}
Summary
Encephaloceles are herniation of cranial content arising from a skull defect. Encephaloceles of the lateral wall of the sphenoid sinus (ELWSS) are uncommon events. In most cases, these cranial hernias are secondary to trauma and craniofacial surgery. Spontaneous forms are even rarer and not well understood. The most adopted hypothesis is a persisting Sternberg's canal, an embryonic remnant connecting the middle cranial fossa and the nasopharynx. ELWSS are usually revealed by cerebrospinal fluid (CSF) leak. Diagnosis of this disease necessitates quick management due to the potential of lethal complications such as meningitis.

We report the case of a spontaneous ELWSS in a 53year-old woman revealed by CSF leak which was
\end{abstract}

successfully managed with a conventional transcranial approach. We focus on the clinical aspect and pathogenesis of the disease, and discuss the main possible surgical approaches.

Keywords: Spontaneous encephalocele, Sphenoid sinus, CSF leak, Transcranial approach

Ann Afr Surg. 2021; 18(1):63-66

DOI: http://dx.doi.org/10.4314/aas.v18i1.12

\section{Conflicts of Interest: None}

\section{Funding: None}

(C) 2021 Author. This work is licensed under the Creative Commons Attribution 4.0 International License.

Sternberg's canal (6). It starts from the sphenoid bone body and the lesser wing and goes downwards to the nasopharynx, creating a connection between the middle cranial fossa and the sphenoid sinus. Encephalocele of the lateral wall of the sphenoid sinus (ELWSS) mainly manifests with CSF rhinorrhea. Meningitis and seizures were also reported (7). This clinical diversity made this pathological entity a multidisciplinary topic, uniting otolaryngologists, neurosurgeons and maxillofacial surgeons.

We report an illustrative case of spontaneous ELWSS in a 53-year-old woman revealed by CSF rhinorrhea, which was managed by a classical transcranial approach. In this paper, we describe the clinical aspect of the 
ELWSS and its possible pathogenesis. We describe the management of the disease using the classical approach and then discuss the different therapeutic approaches.

\section{Case report}

A 53-year-old post-menopausal woman was referred to the neurosurgery department of Mongi Hmida Institute for spontaneous CSF rhinorrhea evolving for three months. Hypertension and dyslipidemia were noted as associated comorbidities. No history of craniofacial trauma or surgery was reported. The patient was obese with a BMI equal to 33.9. Clinical examination found an isolated right CSF rhinorrhea. The patient had already been examined by a head and neck surgery team. Nasal endoscopy showed a clear liquid leak in the right nasal cavity, which was interpreted as CSF after beta transferrin test. CT scan and CT cysternography showed a lateral bony defect of the right wall of the sphenoid sinus associated with protrusion of temporal lobe tissue in the sphenoid sinus (Figures 1 and 2). The patient underwent transcranial resective surgery with dissection of the temporal lobe. The bony defect was identified and the encephalocele was resected. Autologous abdominal fat was already harvested and prepared after para umbilical incision. The defect was repaired using cranial bone and abdominal fat graft (Figures $3 \mathrm{a}$ and $\mathrm{b}$ ). Postoperative recovery was uneventful. CSF dried up in 2 days. The patient was discharged after 3 days. She is asymptomatic after 1 year of follow-up.

\section{Discussion}

Encephalocele of the lateral wall of the sphenoid sinus, also called parasellar sphenoid encephaloceles, consist of the herniation of meninges and brain tissue through a skull defect in the lateral recess of the sphenoid sinus laterally to the foramen rotundum (8). This herniation is either spontaneous or secondary to trauma and craniofacial surgery. Spontaneous ELWSS are rare conditions and limited in the literature to sporadic cases. The presence of a certain predisposing anatomic structure has been evoked as a probable hypothesis behind the genesis of ELWSS. In fact, the sphenoid bone derives from the fusion of several embryonic portions: presphenoid (anterior sphenoid bone), basisphenoid (posterior sphenoid bone), orbitosphenoid (lesser wings) and alisphenoid (lateral part of the sphenoid process and greater wings) (9). Ossification of some cartilaginous portions corresponding to the future lateral wall of the sphenoid sinus happens after birth. If this fusion fails, a connection is created between the middle cranial fossa and the rhinopharynx. This connection, described in 1888 by Sternberg, corresponds to the craniopharyngeal canal (10). Towards puberty, the sphenoid sinus reaches its final pneumatization. If bone reabsorption reaches the Sternberg canal, this represents a week point where encephaloceles can occur (6).

ELWSS are favored by enlargement of the sphenoid bone (6). Obesity, like in this case, has been also reported as a risk factor $(3,11)$. Besides, a slightly higher prevalence in the female gender was recorded $(3,7)$.

CSF rhinorrhea is the most common clinical manifestation of ELWSS (12). In one of the largest studies by Zoli et al. (7), CSF leak was present in 19 out of 23 patients. Likewise, in a recent small series of 7 cases of ELWSS by Gore (13), CSF leak was present in 6 cases. Meningitis is a common complication of longterm ignored CFS leak and could be a revealing presentation $(3,13)$. Temporal lobe seizures are relatively rare (14).

High-resolution CT is an excellent exam to explore bone integrity. It is often the only test needed for the diagnosis of the skull base defect (15). Cysternography associated with CT has a great contribution like in this case. In fact, it shows the contrast movement in active fistula with a success rate reaching $85 \%$ (16). MRI imaging is more reliable in studying soft brain tissue and is recommended alongside CT scan (17).

ELWSS with active rhinorrhea could be lethal conditions due to the high risk of meningitis and encephalitis. Thus, diagnosis of this disease implies quick management. In this case the ELWSS was successfully managed using a transcranial conventional approach. The choice of this classical technique was essentially due to the lack of instruments. Besides, frontotemporal craniotomy offers excellent exposure, allowing dissection of the temporal lobe and reconstruction of the bony defect $(3,18)$. Tsutsumi et al. managed successfully two cases of ELWSS using the 


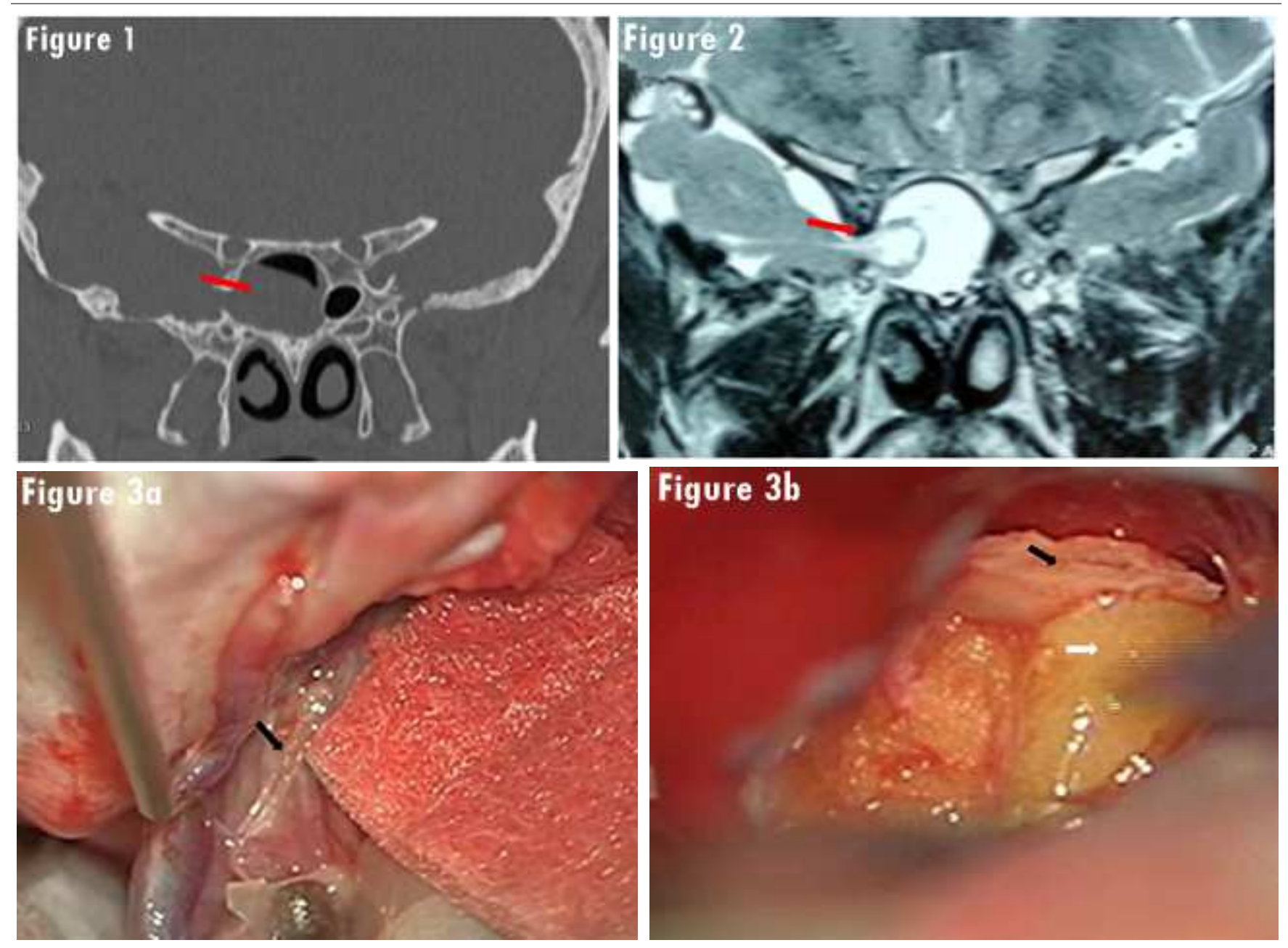

Figure 1: CT scan showing a lateral bony defect of the right wall of the sphenoid sinus associated with protrusion of temporal lobe tissue in the sphenoid sinus; Figure 2: CT Cysternography showing a lateral bony defect of the right wall of the sphenoid sinus associated with protrusion of temporal lobe tissue in the sphenoid sinus; Figure 3A and B: Closure of the defect using cranial bone and abdominal fat

transcranial approach (19). The endoscopic approach is an elegant non-invasive alternative to the transcranial approach. In well-trained hands, it offers a direct visualization, allowing removal of the herniation and repair of the defect. The lateral localization of the defect represents the main difficulty when using this technique, according to Tabaee et al. (20). To avoid this problem, Bolger proposed in 2005 the transpterygoid approach which offers a direct exposure of lateral recess of sphenoid bone (8). Zoli et al. (7) managed successfully 23 cases of ELWSS using the endoscopic approach. A multilayer closure with fascia lata, mucoperiosteum and bone or fat graft was performed. Gore applied the same approach with the use of alloderm and nasoseptal flap for reconstruction (13). The choice of the surgical technique depends roughly on surgical skills and anatomic conditions such as degree of sphenoid sinus pneumatization and size of the encephalocele. Postoperative complications consist essentially in the persistence of CSF leak, epileptic seizures and infections. Most of these complications were reported with the endoscopic nasal approach $(7,20)$.

\section{Conclusion}

Spontaneous ELWSS is a rare condition that usually manifests by CSF rhinorrhea. A persisting embryonic remnant called Sternberg's canal could explain the genesis of this disease. The optimal management is still 
controversial due to the scarcity of cases. A trend towards the endoscopic approach is frequently recorded.

\section{Informed consent}

Written informed consent was obtained from the patient.

\section{References}

1. Kubo A, Sakata K, Maegawa J, et al. Transethmoidal meningoencephalocele in an elderly woman. Case report. Neurol Med Chir. 2005; 45(6):322-6.

2. Arai A, Mizukawa K, Nishihara M, et al. Spontaneous cerebrospinal fluid rhinorrhea associated with a far lateral temporal encephalocele--case report. Neurol Med Chir. 2010; 50(3):243-5.

3. Bendersky DC, Landriel FA, Ajler PM, et al. Sternberg's canal as a cause of encephalocele within the lateral recess of the sphenoid sinus: A report of two cases. Surg Neurol Int. 2011; 2:171.

4. Bikmaz K, Cosar M, Iplikcioglu AC, et al. Spontaneous cerebrospinal fluid rhinorrhoea due to temporosphenoidal encephalocele. J Clin Neurosci. 2005; 12(7):827-9.

5. Tomaszewska M, Brozek-Madry E, Krzeski A. Spontaneous sphenoid sinus cerebrospinal fluid leak and meningoencephalocele - are they due to patent Sternberg's canal? Wideochirurgia $\mathrm{i}$ inne techniki maloinwazyjne = Videosurgery and other mini-invasive techniques. 2015; 10(2):347-58.

6. Schick B, Brors D, Prescher A. Sternberg's canal--cause of congenital sphenoidal meningocele. Eur Arch Oto-rhinolaryngol. 2000; 257(8):430-2.

7. Zoli M, Farneti P, Ghirelli M, et al. Meningocele and Meningoencephalocele of the lateral wall of sphenoidal sinus: the role of the endoscopic Endonasal Surg. World Neurosurg. 2016; 87:91-7.

8. Bolger WE. Endoscopic transpterygoid approach to the lateral sphenoid recess: surgical approach and clinical experience. Otolaryngol--Head Neck Surg. 2005; 133(1):20-6.
9. Nemzek WR, Brodie HA, Hecht ST, et al. MR, CT, and plain film imaging of the developing skull base in fetal specimens. Am J Neurorad. 2000; 21(9):1699-706.

10. Sternber M. Ein bisher noch nicht beschriebener Kanal im Keilbein des Menschen. Anat Anz. 1888; 3:784-5.

11. Castelnuovo P, Dallan I, Pistochini A, et al. Endonasal endoscopic repair of Sternberg's canal cerebrospinal fluid leaks. Laryngoscope. 2007; 117(2):345-9.

12. Lai SY, Kennedy DW, Bolger WE. Sphenoid encephaloceles: disease management and identification of lesions within the lateral recess of the sphenoid sinus. Laryngoscope. 2002; 112(10):1800-5.

13. Gore MR. Endoscopic repair of lateral sphenoid Encephaloceles: a case series. BMC Ear Nose Throat Disord. 2017; 17:11.

14. Faulkner HJ, Sandeman DR, Love S, et al. Epilepsy surgery for refractory epilepsy due to encephalocele: a case report and review of the literature. Epileptic Disord. 2010; 12(2):160-6.

15. Lloyd MNH, Kimber PM, Burrows EH. Post-traumatic cerebrospinal fluid rhinorrhoea: Modern high-definition computed tomography is all that is required for the effective demonstration of the site of leakage. Clin Rad. 1994; 49(2):1003 .

16. Nabawi P, Mafee M, Phillips J, et al. The success rate of metrizamide CT cisternography in the evaluation of cerebrospinal fluid (CSF) rhinorrhea. Comp Rad. 1982; 6(6):343-54.

17. Johnson DB, Brennan P, Toland J, et al. Magnetic resonance imaging in the evaluation of cerebrospinal fluid fistulae. Clin Radiol. 1996; 51(12):837-41.

18. Landreneau FE, Mickey B, Coimbra C. Surgical treatment of cerebrospinal fluid fistulae involving lateral extension of the sphenoid sinus. Neurosurgery. 1998; 42(5):1101-4.

19. Tsutsumi K, Asano T, Shigeno T, et al. Transcranial approach for transsphenoidal encephalocele: report of two cases. Surg Neurol. 1999; 51(3):252-7.

20. Tabaee A, Anand VK, Cappabianca P, et al. Endoscopic management of spontaneous meningoencephalocele of the lateral sphenoid sinus. J Neurosurg. 2010; 112(5):1070-7. 